\title{
Effects of wortmannin, sodium nitroprusside, insulin, genistein, and guanosine triphosphate on chemotaxis and cell growth of Entodinium caudatum, Epidinium caudatum, and mixed ruminal protozoa
}

\author{
H. L. Diaz, ${ }^{\star 1}$ J. R. Knapp,† S. K. R. Karnati, ${ }^{*}$ B. A. Dehority, ${ }^{*}$ and J. L. Firkins ${ }^{\star 2}$ \\ *Department of Animal Sciences, The Ohio State University, Columbus 43210 \\ †Fox Hollow Consulting LLC, Columbus, OH 43201
}

\begin{abstract}
The mechanisms by which ruminal protozoa sense and migrate toward nutrients are not fully understood. Chemotaxis by many diverse eukaryotic cells is mediated by phosphatidylinositol-3-kinase, which is highly conserved in receptor tyrosine kinase (RTK) signaling pathways and consistently inhibited by wortmannin. In experiment 1a, increasing the concentration of wortmannin inhibited cell growth nonlinearly at $24 \mathrm{~h}$ of a culture of the rumen protozoan Entodinium caudatum, but high variability prevented growth inhibition of Epidinium caudatum from reaching significance. In experiment $1 \mathrm{~b}$, increasing the insulin concentration recovered 24-h cell counts for both cultures, depending on wortmannin concentration. In experiment 2, addition of sodium nitroprusside (Snp; activator of protein kinase $\mathrm{G}$ for cilial beat reversal in nonrumen ciliate models) at $500 \mu M$ or wortmannin at $200 \mu M$ in beakers containing rumen fluid decreased random swimming by mixed entodiniomorphids into capillary tubes (inserted into beakers) containing saline. Both Snp and wortmannin increased chemotaxis into tubes containing glucose compared with the beaker control. For isotrichids, beaker treatments had no response. Glucose increased chemotaxis, but peptides decreased chemotaxis even when combined with glucose. In experiment 3, we assessed preincubation of genistein (a purported RTK blocker in nonrumen ciliate models) at 40 or $400 \mu M$ in beakers and guanosine triphosphate (GTP; a universal chemorepellent in nonrumen ciliate models, perhaps mediated through an RTK) at 10 or $100 \mu M$ combined with glucose in capillary tubes. Neither genistein nor GTP affected chemotaxis toward glucose for entodiniomorphids. However, GTP at $100 \mu M$ reduced chemo-
\end{abstract}

\footnotetext{
Received August 27, 2013.

Accepted January 7, 2014.

${ }^{1}$ Current address: Procter and Gamble, 8700 Mason-Montgomery Road, Mason, $\mathrm{OH} 45040$.

${ }^{2}$ Corresponding author: firkins.1@osu.edu
}

taxis toward glucose for isotrichids. After the animal is fed, isotrichids that are depleted in glycogen migrate to the dorsal area of the rumen, and the rapid uptake of sugars is enhanced through strong chemotaxis but can be reversed by peptides or GTP. In contrast, entodiniomorphids are less intensely chemoattracted to glucose than isotrichids but are chemoattracted to peptides. Entodiniomorphids' chemoattraction appears to be integrated with slower but prolonged availability of energy from digesting starch and fiber.

Key words: rumen protozoa, chemotaxis, wortmannin, insulin

\section{INTRODUCTION}

Microbial protein synthesis in the rumen contributes up to $70 \%$ of the protein entering the small intestine of ruminants (Russell and Rychlik, 2001). Rumen protozoa have been widely studied to improve efficiency of protein usage (Hristov and Jouany, 2005). Inaccuracy and imprecision in the prediction of the ruminal biomass, autolysis, and outflow of protozoal protein might encourage overfeeding of dietary $\mathrm{CP}$ to maintain the productivity of high-producing animals (Firkins et al., 2006, 2007). Although more recent models predict greater protozoal outflow from the rumen associated with the particulate phase because of entrapment and attachment to particles (Hook et al., 2012), Diaz et al. (2014b) suggested that passage of entodiniomorphids with the particulate phase resulted from moderate but continual chemoattraction to soluble sugars and peptides in a higher gradient in the potentially degradable fraction of ingesta.

Williams (1979) noted that Dasytricha, an isotrichid, can sense and be chemoattracted to soluble sugars. Glucose- and fructose-containing sugars (but not lactose or mannose) are readily metabolized by isotrichids (Dehority, 2003), which rapidly assimilate storage polysaccharide (Hall, 2011) and then sediment to the dorsal floor of the reticulorumen (Abe et al., 1981). Increased frequency of feeding should synchronize migration be- 
havior that is distributed among isotrichid populations (Dehority, 2003), thus increasing the potential for isotrichids to pass out of the rumen. Greater understanding of mechanisms by which migration and chemotaxis by isotrichids would improve our ability to assess the effect of their sequestration in the rumen on efficiency of protein usage by ruminants (Firkins and Yu, 2006). In addition to cilial action for cell motility, specific cilia near the vestibulum of Dasytricha were projected to aid ingestion of very small particulates but to a lesser extent compared with ingestion of larger particles by entodiniomorphids (Paul et al., 1989). Although entodiniomorphids have cilia only near their anterior region, specific cilial bands aid propulsion of starch granules and fibrous particles inside the cytopharynx (Williams and Coleman, 1992).

Ruminal protozoa have received much less attention regarding metabolic regulation of growth and motility compared with freshwater ciliates. Tetrahymena thermophila, a holotrich (completely ciliated, as are the isotrichids), actively predates bacteria and has an insulin-like external receptor that is coupled to an internal tyrosine kinase (RTK) for signal transduction (Christensen et al., 2003) and regulation of various growth-related metabolic processes (Leondaritis et al., 2011). Insulin's role has been described for its potential to bind to a receptor, rescue growth after starvation, and potentially even be endogenously produced in Tetrahymena (Csaba et al., 2008). This ciliate can even be chemoattracted to insulin (Leick et al., 2001). Ruminal ciliates are potentially stimulated by insulin (Kisidayová and Varadyova, 2005) but have not been assessed for responses to pharmacological agents. Wortmannin is a hydrophobic fungal metabolite that blocks numerous insulin-stimulated responses in human and mammalian cell types (Cho and Park, 2008). For example, as presumptively mediated through phosphatidylinositol 3-kinase (PI3K), insulin rescued apoptotic signaling responses of rat liver cells, but wortmannin blocked this rescue (Pagliassotti et al., 2007). In the eukaryotic ciliate Tetrahymena, wortmannin has many potential ways to inhibit growth, ranging from interrupted vesicle trafficking (Leondaritis et al., 2005) and arrested macronuclear formation (Smith et al., 2004) to physical blockage (Kovacs and Pallinger, 2003). To our knowledge, though, insulin has not been assessed for a potential role to rescue growth after wortmannin inhibition in any ciliate (or, conversely, for wortmannin to block insulin-stimulated growth).

Sodium nitroprusside (Snp) activates protein kinase G (PKG), which stimulates directional turning in Tetrahymena through cilial beating frequency and reversal (Leick and Chen, 2004). Ciliates have mechanoreceptors that signal directional turning after bumping into obstacles (Gonda et al., 2007), and this response in rumen ciliates can readily be observed microscopically. Chemoattraction to bacterial protein hydrolysates was inhibited by genistein's blockage of an RTK, which prevented turning toward the chemoattractant gradient (Leick and Chen, 2004). Although guanosine triphosphate (GTP) might bind to a purinergic G-proteincoupled receptor in the nonrumen ciliate Paramecium (Sehring and Plattner, 2004), GTP is also thought to bind to an RTK in Tetrahymena, signaling chemorepellence that was reversed by genistein (Bartholomew et al., 2008). Genistein is a phytoestrogen isoflavone found in certain feeds (e.g., soybeans) that presumably would be exposed to ruminal protozoa because it can be degraded by gut bacteria (Renouf and Hendrich, 2011).

The objective of experiment 1a was to study the dose response of the PI3K inhibitor wortmannin in Entodinium caudatum and Epidinium caudatum cultures. We hypothesized that wortmannin would inhibit growth when administered at feeding time by blunting chemotactic swimming toward substrate (Leick and Chen, 2004) or by interfering with phagolysosomal digestion processes (Leondaritis et al., 2005) inferred from Tetrahymena models. The objective of experiment $1 \mathrm{~b}$ was to study the effect of wortmannin without or with insulin in those cultures, with the hypothesis that increasing concentrations of insulin would rescue cellular growth after wortmannin inhibition.

Diaz et al. (2014b) previously documented chemotaxis for both isotrichids and entodiniomorphids toward glucose and peptides. Herein, we hypothesized interactions that would vary according to the presence of eukaryotic activators or inhibitors in experiment 2. Specifically, we hypothesized that insulin would increase chemotaxis toward glucose and peptides; that wortmannin would decrease chemotaxis toward glucose and peptides, especially for entodiniomorphids; and that Snp would increase chemotaxis toward glucose and peptides by both entodiniomorphids and isotrichids.

In experiment 3, we hypothesized that GTP would reverse chemoattraction toward glucose. However, if ruminal protozoa were previously incubated with genistein as a general RTK blocker, we hypothesized that the avoidance by GTP would be blunted in the highly chemotactic isotrichids but less so in entodiniomorphids.

\section{MATERIALS AND METHODS}

\section{Experiment 1: Dose Responsiveness of Wortmannin and Insulin}

Cryopreserved Entodinium caudatum and Epidinium caudatum were provided by Burk Dehority (The Ohio 
State University, Wooster). These are monocultures of protozoa but also contain bacteria and probably archaea. The En. caudatum culture was originally purchased from the European Rumen Ciliate Culture Collection and used in previous studies in our laboratory (Sylvester et al., 2009). The Ep. caudatum was isolated from a steer and described by Dehority (2010). Protozoal medium SP was used for both En. caudatum and Ep. caudatum (Dehority, 1998). Medium was dispensed into $16-\times 150-\mathrm{mm}$ tubes, autoclaved for 20 min at $121^{\circ} \mathrm{C}$, and stored at room temperature until use. Substrate for cultures was a suspension containing $1.5 \%$ (wt/vol) ground wheat and $1 \%(\mathrm{wt} / \mathrm{vol})$ dried orchardgrass prepared in distilled water and gassed with $\mathrm{O}_{2}$-free $\mathrm{CO}_{2}$. Orchardgrass was ground at room temperature using a Wiley mill (Arthur H. Thomas, Philadelphia, PA) to pass through a 1-mm screen. All ingredients were further processed for $3 \mathrm{~min}$ in a coffee grinder to make a fine powder, which was stored at $-20^{\circ} \mathrm{C}$ until use. All cultures were fed once daily at $0900 \mathrm{~h}$ at a feeding rate of $12 \mu \mathrm{L} / \mathrm{mL}$ of culture.

Protozoal culture volumes were increased from 10 to $320 \mathrm{~mL}$ by adding an equal volume of fresh medium every $3 \mathrm{~d}$ and maintained in 1,000-mL glass Pyrex bottles sealed with number-7 rubber stoppers. The $320-\mathrm{mL}$ culture volumes were maintained by removing $160 \mathrm{~mL}$ of culture and adding $160 \mathrm{~mL}$ of fresh medium every 3 d. All cultures were maintained for at least 4 transfers before experiments started. On d 0 of the experiment, with repeated gentle mixing, $10 \mathrm{~mL}$ of each culture was removed from the respective $320 \mathrm{~mL}$ of stock culture using a wide-mouth glass pipette and placed into $16-x$ $150-\mathrm{mm}$ tubes containing $10 \mathrm{~mL}$ of fresh medium and substrate plus respective treatments to be studied.

For experiment 1a, our aim was to demonstrate doseresponsive inhibition by $0,0.20,2.0$, and $20 \mu M$ wortmannin ( $>98 \%$ purity, purchased from Cell Signaling Technology, Danvers, MA) for $30 \mathrm{~min}$ before feeding, after which cells were incubated for $24 \mathrm{~h}$. Wortmannin dosage ranged from 0.10 to $10 \mu M$ for the aerobic ciliate Tetrahymena (Kovacs and Pallinger, 2003; Smith et al., 2004; Leondaritis et al., 2005; Nam et al., 2009). Leondaritis et al. (2005) used similar times for wortmannin incubation and the same concentration $(0.1 \%)$ of dimethyl sulfoxide (DMSO) vehicle and also explained why wortmannin was more consistently inhibitory than was another common eukaryotic PI3K inhibitor, LY294002.

Based on the results from experiment 1a, the aims of experiment $1 \mathrm{~b}$ were to incubate En. caudatum and Ep. caudatum cultures with 0 (control), 0.20, and 2.0 $\mu M$ wortmannin for $30 \mathrm{~min}$, after which cultures were fed simultaneously with administration of bovine insulin (>27 USP units/mg; Sigma-Aldrich, St. Louis,
MO) to provide final concentrations of $0,0.10,0.50$, and $2.5 \mu \mathrm{M}$. Insulin concentrations were based on a range from studies with Tetrahymena (Christopher and Sundermann, 1992) and rumen ciliates (Kisidayová and Varadyova, 2005). After insulin addition, triplicate samples of $1.5 \mathrm{~mL}$ were taken at 0 and $24 \mathrm{~h}$, placed in 2.0-mL microcentrifuge tubes, preserved with formalin, and stained using brilliant green dye for counting.

Cells were quantified using 2 different methods. For experiments 1a and 1b, En. caudatum cells were counted in a Sedgewick-Rafter counting chamber (Dehority, 1993). For both experiments, the Ep. caudatum cultures were counted as described by Sylvester et al. (2009) by transferring 2 replicate $0.5-\mathrm{mL}$ aliquots of stained culture in 10 separate $50-\mu \mathrm{L}$ spots onto a $25-\times 10-\mathrm{cm}$ piece of clear acrylic plastic and covering with glass coverslips. Cells were counted at $20 \times$ magnification using a dissecting microscope. To represent wortmannin inhibition and insulin stimulation of cell counts on the same scale for both cultures, means for experiments $1 \mathrm{a}$ and $1 \mathrm{~b}$ are reported as the proportion of 0-h counts (taken just before the addition of treatments). Triplicates of counts at $24 \mathrm{~h}$ (normalized for 0-h counts) were analyzed using the Mixed procedure of SAS (version 8.2; SAS Institute Inc., Cary, NC). A randomized complete block design included the effects of treatments and random effects of 3 replicate incubations. Polynomial contrasts for linear, quadratic, cubic, and quartic (only in experiment 1a) were corrected for unequal spacing of wortmannin (experiment 1a) or insulin (experiment 1b) concentrations using Proc IML to determine contrast coefficients. To protect against Type II error (Berndtson, 1991) resulting from the high variation in cell counts, significance was declared at $P \leq 0.10$.

\section{Experiment 2: Interactions of Beaker Inhibitors with Glucose or Peptide Chemoattractants in Capillary Tubes}

Rumen fluid from 2 rumen-cannulated Holstein cows was collected after feeding a diet consisting of mixed forage and grain (50:50). The animals were maintained in accordance with The Ohio State University animal care and use guidelines. Ruminal fluid was collected, filtered through 2 layers of cheesecloth, transported to the laboratory, pooled, and flocculated for $30 \mathrm{~min}$, as described in the companion paper (Diaz et al., 2014b). Then, 20-mL aliquots of the ruminal fluid were placed in $50-\mathrm{mL}$ beakers and preincubated in an anaerobic chamber for 0 and $3 \mathrm{~h}$ with control, 2.5 or $25 \mu M$ insulin (Sigma-Aldrich), 50 or $500 \mu M$ Snp (99\% purity, Sigma-Aldrich), and 20 or $200 \mu M$ wortmannin (>98\% purity, Sigma-Aldrich). The dosage range of Snp was based on studies with Tetrahymena (Leick and Chen, 
2004). Wortmannin dosage was based on results from experiment 1 . All beaker treatments, including the control, contained DMSO at a final concentration of $0.1 \%$, which is consistent with the manufacturers' directions for each purchased compound. To conduct the chemotaxis assay, capillary tubes $(75 \mathrm{~mm})$ that were empty and unsealed (UN) were used to correct for variation among beakers, as described previously (Diaz et al., 2014b). Additional capillary tubes were filled with $0.9 \%$ $\mathrm{NaCl}$ saline (Sal; control for random swimming), $1 \mathrm{M}$ glucose (Glc), $1 \mathrm{~g} / \mathrm{L}$ soluble soy peptides (Pep), or a combination of Glc + Pep dissolved in saline after which the capillary tubes were sealed with clay at the top (the bottom was left open for protozoal entry) before insertion into beakers. The chemotaxis methods, rationale for choosing soy peptides, and the dosages for Glc and Pep were based on results from Diaz et al. (2014b). As described in that report, triplicates of 20min counts (adjusted for 0-min counts) were normalized to $\log _{10}$ for the UN capillary tubes. Counts from all other capillary treatments (that were sealed) were covariate-adjusted to the counts in UN capillary tubes before $\log _{10}$ normalization, as justified previously.

Data were analyzed using the Mixed procedure of SAS (version 8.2; SAS Institute Inc.) in a randomized incomplete block design (duplicated tubes and blocked for 3 replicate runs). The 7 beaker treatments were control, 2.5 or $25 \mu M$ insulin, 50 or $500 \mu M$ Snp, and 20 or $200 \mu M$ wortmannin. Data for unsealed capillary tubes were analyzed to test effects of beaker treatment using Fisher's F test-protected least significant difference (LSD). Data for the sealed capillary tube treatments were analyzed according to a $7 \times 4$ factorial arrangement. The 7 beaker treatments were those described above, and the 4 capillary tube treatments were arranged in a $2 \times 2$ factorial: Sal, $1 M$ Glc, $1 \mathrm{~g} / \mathrm{L}$ Pep, or Glu + Pep dissolved in saline. If a beaker treatment $\times$ capillary tube treatment interaction was detected $(P$ $\leq 0.05$; entodiniomorphids), we used the SLICE option to protect the LSD comparison of beaker treatments within capillary treatment. Preplanned orthogonal contrasts tested the main effects of glucose, peptides, and their interaction. Contrasts were performed per beaker treatment in the presence of beaker treatment $x$ capillary tube treatment interactions $(P \leq 0.05$; entodiniomorphids) or were done for the main effect means of capillary tube treatments when no interaction was detected ( $P>0.10$; isotrichids).

\section{Experiment 3: Preincubation with Genistein in Beakers and Use of GTP as a Chemorepellant in Capillary Tubes}

Ruminal fluid was collected $3 \mathrm{~h}$ after feeding and flocculated as described for experiment 2. Then, $20-\mathrm{mL}$ aliquots of flocculated rumen fluid were placed in 50$\mathrm{mL}$ beakers and anaerobically preincubated for $30 \mathrm{~min}$ with 0, 40, or $400 \mu M$ genistein (98\% purity, SigmaAldrich). Leick et al. (1997) assessed the role of RTK in Tetrahymena thermophila using genistein at $100 \mu \mathrm{M}$. After preincubation, a chemotaxis assay was conducted as described previously using capillary tubes that were unfilled and unsealed or filled with $0.9 \%$ Sal, $1 M$ Glc, 1 $M$ Glc plus $10 \mu M$ GTP, or $1 M$ Glc plus $100 \mu M$ GTP (95\% purity, Sigma-Aldrich). Concentrations of GTP for this experiment were based on research conducted by Sehring and Plattner (2004) and Bartholomew et al. (2008) for Paramecium $(15 \mu M)$ and Tetrahymena (100 $\mu M)$, respectively.

Data were $\log _{10}$-normalized before analysis using the Mixed procedure of SAS (version 8.2) in a randomized complete block design (blocked for 3 replicate runs). Data for UN capillary tubes were compared by Fisher's protected LSD. All sealed capillary treatments were covariate-adjusted to their respective $\mathrm{UN}$ tubes and analyzed according to a $3 \times 4$ factorial arrangement with 3 beaker treatments [genistein at 0 (control), 40, or $400 \mu M]$ or 4 capillary treatments (saline, $1 M$ Glc, $1 M$ Glc $+10 \mu M$ GTP, or $1 M$ Glc $+100 \mu M$ GTP dissolved in saline). Because we detected no beaker treatment $\times$ capillary tube treatment interactions $(P$ $>0.10$ ), main effects of beaker and capillary tube solution were compared by Fisher's protected LSD with significance declared at $P \leq 0.05$.

\section{RESULTS AND DISCUSSION}

\section{Experiment 1: Dose Responsiveness of Wortmannin and Insulin}

Wortmannin at $0.20 \mu M$ or higher concentrations decreased normalized 24-h counts below 1.0 for both cultures, indicating inhibition (i.e., less growth than lysis; Figure 1). Polynomial contrasts were $P<0.01$ for linear, quadratic, and cubic contrasts (and $P=0.06$ for quartic) for En. caudatum, demonstrating maximum inhibition by wortmannin at 2 and $20 \mu M$. Despite similar numerical responses to En. caudatum, the higher variation (greater SE) for Ep. caudatum prevented detection of significance $(P>0.20)$ for dose-responsive inhibition by wortmannin. To our knowledge, wortmannin has not been used in experiments with ruminal protozoa. We expect our results to represent specific PI3K inhibition, not some general toxicity, because Tetrahymena cultures have been incubated with wortmannin for $24 \mathrm{~h}$ and with similar conclusions (Nam et al., 2009). In that nonrumen ciliate, wortmannin is recognized as a potent and specific inhibitor of PI3K and can interfere with normal vesicle trafficking (Leondaritis et al., 2005), and 


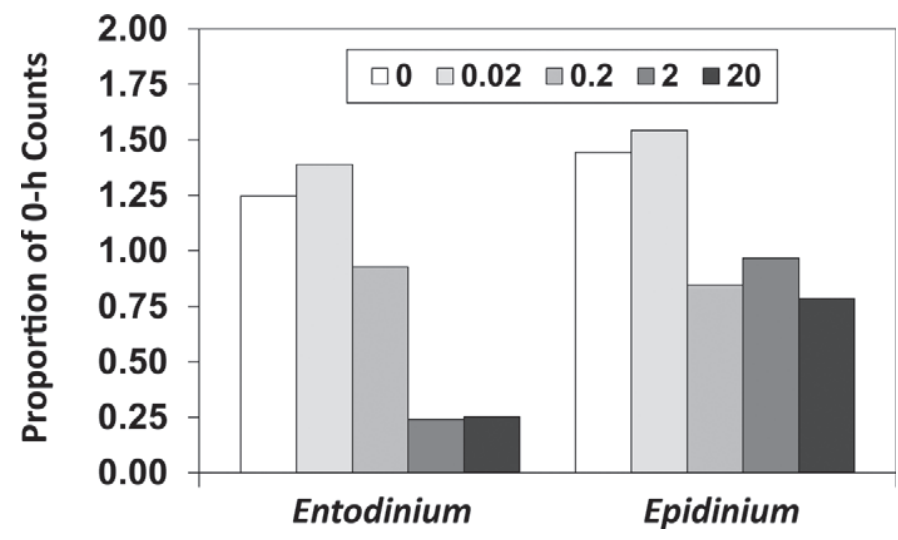

Figure 1. Counts at $24 \mathrm{~h}$ expressed as a proportion of 0 -h counts for Entodinium caudatum and Epidinium caudatum cultures incubated with $0,0.02,2.0$, or $20 \mu M$ wortmannin in experiment 1a. For Entodinium $(\mathrm{SE}=0.05)$, wortmannin responses were linear $(P<$ $0.01)$, quadratic $(P<0.01)$, cubic $(P<0.01)$, and quartic $(P=0.06)$. Epidinium caudatum $(\mathrm{SE}=0.41)$ polynomial contrasts were $P>0.20$.

inositide signaling appears to be highly conserved in ciliates (Leondaritis et al., 2011). Therefore, despite the lack of difference for the approximately $40 \%$ reduction in counts for Ep. caudatum, the 0.20 and $2.0 \mu \mathrm{M}$ dosages of wortmannin were chosen in subsequent experiments to assess the potential rescue from wortmannin inhibition with increasing concentrations of insulin.

In previous pilot studies, we were not able to demonstrate any activity by a commonly used eukaryotic inhibitor of ribosomal translation, rapamycin (data not shown). There is little published research with ciliates. Although the flagellated protozoal parasite Giardia conserved most elements of target of rapamycin signaling (considered as evolutionarily ancient), rapamycin binding sites might be absent compared with those conserved in higher eukaryotes (Morrison et al., 2002). However, wortmannin inhibited growth in that protozoan (Hernandez et al., 2007).

A negative control had only the DMSO vehicle but no insulin in experiment $1 \mathrm{~b}$ (Figures $2 \mathrm{~A}$ and $2 \mathrm{~B}$ ). Compared with those in the negative control without wortmannin or insulin, En. caudatum counts at $24 \mathrm{~h}$ (Figure 2A) were numerically lower for $0.20 \mu M$ wortmannin with 0 or $0.10 \mu \mathrm{M}$ insulin but increased with increasing insulin concentrations (even to be numerically greater than the negative control for insulin at $2.5 \mu M$ ), resulting in a linear $(P=0.08)$ response. However, the wortmannin at $2.0 \mu M$ lowered cell counts further compared with the negative control, and responsiveness to insulin was not detected. For Ep. caudatum cultures (Figure 2B), insulin had no effect $(P>0.10)$ at $0.2 \mu M$ wortmannin, but increasing insulin resulted in quadratic responses $(P=0.03)$ for $2.0 \mu M$ wortmannin.

Although vaccines have been tested against ruminal protozoa (Williams et al., 2008), documenting recov- ery of blood proteins in ruminal fluid, the response to insulin by ruminal protozoa is probably not an intentional consequence. Insulin and various other protein hormones have caused a widespread response in environmental microbes (Lenard, 1992), particularly for Tetrahymena species of aerobic ciliates, even at extremely dilute concentrations (Christensen et al., 2003; Csaba et al., 2006). In these environments, the consistent responsiveness to insulin and various other growth factors suggests a nonspecific external receptor with a conserved transmembrane RTK or perhaps internalized insulin responses (Csaba et al., 2008). A single dosage of insulin into a culture of En. caudatum increased VFA
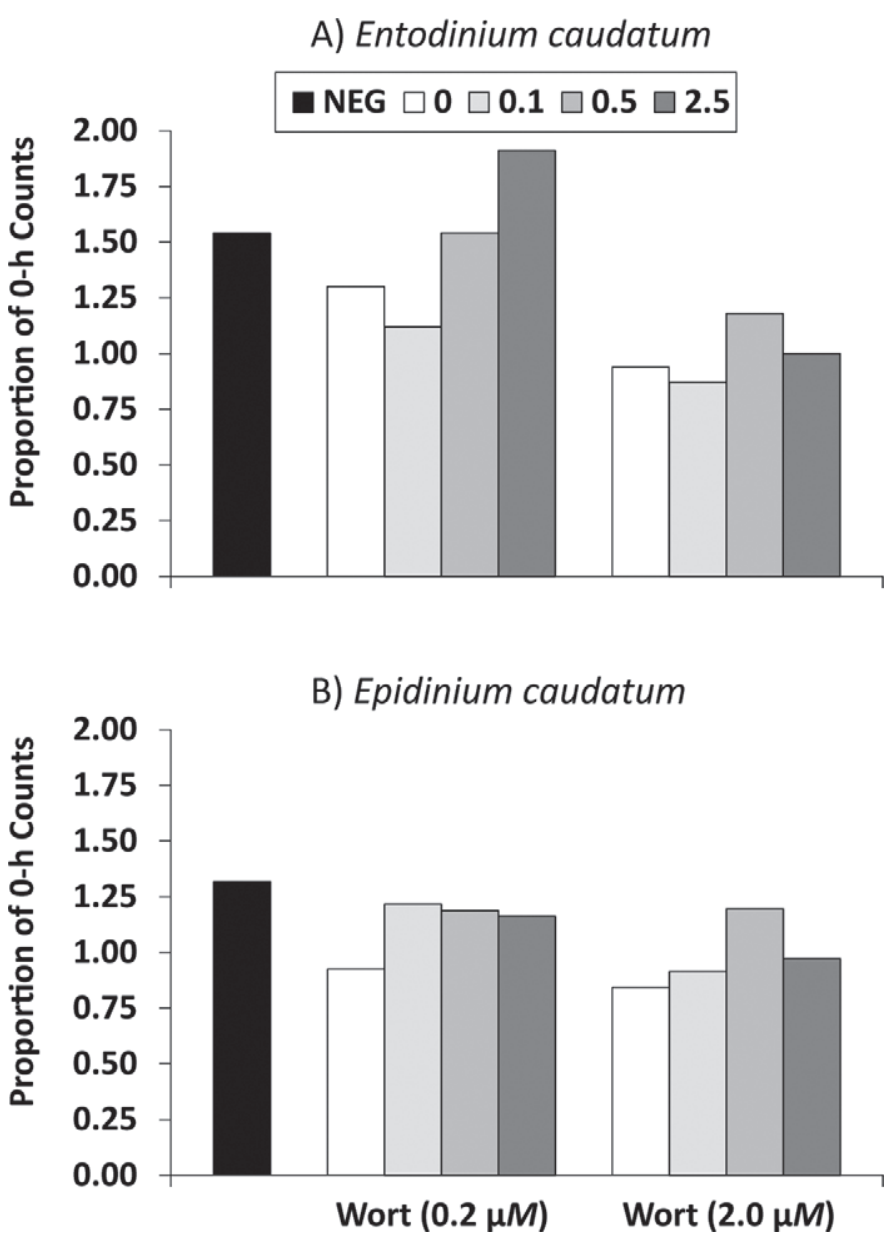

Figure 2. Counts at $24 \mathrm{~h}$ expressed as a proportion of 0 -h counts for Entodinium caudatum (A) and Epidinium caudatum (B) preincubated for $30 \mathrm{~min}$ with 0 [negative control (NEG), which also had no insulin], 0.2 , or $2.0 \mu \mathrm{M}$ wortmannin (Wort) and the subsequent 24 -h incubation with insulin to provide a final concentration of $0,0.1,0.5$, or $2.5 \mu \mathrm{M}$ in experiment $1 \mathrm{~b}$. In panel $\mathrm{A}$, for $0.2 \mu M$ wortmannin, the linear effect of insulin concentration was $P=0.08$ (other contrasts, $P>0.10$ ); for $2.0 \mu M$ wortmannin, all contrasts were $P>0.10$. The pooled SE was 0.49 . In panel $\mathrm{B}$, for $0.2 \mu M$ wortmannin, all contrasts were $P>0.10$; for $2.0 \mu M$ wortmannin, the quadratic effect of insulin concentration was $P=0.03$ (other contrasts, $P>0.10$ ). The pooled SE was 0.12 
production by $158 \%$ but did not affect growth (Kisidayová and Varadyova, 2005). In that study, however, the transfer interval was longer than ours, and increasing time since last transfer can limit growth regardless of increasing substrate supply (Dehority, 2004).

\section{Experiment 2: Interactions of Beaker Inhibitors with Glucose or Peptide Chemoattractants in Capillary Tubes}

For entodiniomorphids (Table 1), within the column for the UN capillary tubes and when compared with the beaker control, insulin at $25 \mu M$ increased $(P \leq 0.05)$ $\log _{10}$ counts, but wortmannin at $200 \mu M$ decreased $(P \leq 0.05)$ counts. In Tetrahymena, insulin should increase cell growth through tyrosine kinase signaling (Christensen et al., 2003). Wortmannin should not be generally toxic (Deli et al., 2008); rather, its inhibition of PI3K documents mechanistic roles in digestive vacuole trafficking (Leondaritis et al., 2011), cellular division processes (Smith et al., 2004), or even morphology of daughter cells (Kaczanowska et al., 2008) in Tetrahymena. Assuming conserved wortmannin specificity toward PI3K in rumen ciliates, the results for UN capillary tubes from experiment 2 support insulin's likely rescue of wortmannin-driven inhibition of growth by rumen entodiniomorphid cultures (experiment $1 \mathrm{~b}$ ).

The changes in counts in the UN capillary tubes should represent changes in cell counts in the beakers resulting from administered treatments. To ascertain if these results were associated with chemotaxis, the sealed capillary tubes were covariate-adjusted to UN for entodiniomorphids (Table 1$)$. The interaction $(P$ $<0.01$ ) among counts between preincubation beaker treatments and capillary chemosensory treatments was evaluated by comparing means by LSD within capillary tube treatments that had a significant slice. Within the Sal column, the $500 \mu M$ concentration of Snp and the $200 \mu M$ concentration of wortmannin decreased $(P \leq$ $0.05)$ counts compared with the beaker control treatment. In contrast to Sal, the higher dosages of the Snp and wortmannin treatments increased $(P \leq 0.05)$ chemotaxis compared with the beaker control treatment within the Glc column. We expected Snp to increase chemotactic responsiveness through PKG signaling (Leick and Chen, 2004), potentially promoting circling behavior rather than swimming toward the open end of the sealed capillary tubes filled with saline (no chemoattractant). Wortmannin decreased chemotaxis by Tetrahymena pyriformis without affecting motility (Nam et al., 2009); thus, response of wortmannin to increase protozoal chemotaxis to glucose was unexpected. As explained previously, wortmannin should disrupt digestive vacuole trafficking and availability of energy, likely explaining the lower counts in the saline capillary tubes (lower ATP availability), whereas this same lower energy state could enhance chemotaxis toward particles. Diaz et al. (2014a) subsequently documented

Table 1. $\log _{10}$ counts of entodiniomorphids in empty and unsealed (UN) capillary tubes or in capillary tubes containing saline or chemosensing compounds placed in beakers containing rumen fluid that was preincubated for $3 \mathrm{~h}$ with sensitizing compounds in experiment 2

\begin{tabular}{|c|c|c|c|c|c|c|c|c|}
\hline \multirow{2}{*}{$\begin{array}{l}\text { Beaker } \\
\text { treatment }^{1}\end{array}$} & \multicolumn{5}{|c|}{ Capillary tube treatments ${ }^{2}$} & & & \\
\hline & $\mathrm{UN}$ & Sal & Glc & Pep & $\mathrm{Glc}+\mathrm{Pep}$ & Glc & Pep & Glc $\times$ Pep \\
\hline Control & $3.56^{\mathrm{b}}$ & 2.42 & 2.71 & 2.90 & 3.21 & $<0.01$ & $<0.01$ & NS \\
\hline Insulin, $2.5 \mu M$ & $3.60^{\mathrm{b}}$ & 2.48 & 2.86 & 2.70 & 3.11 & $<0.01$ & $<0.01$ & NS \\
\hline Insulin, $25 \mu M$ & $3.73^{\mathrm{a}}$ & 2.28 & 2.70 & 2.68 & 3.04 & $<0.01$ & $<0.01$ & NS \\
\hline Wort, $20 \mu M$ & $3.53^{\mathrm{bc}}$ & 2.52 & 2.92 & 2.86 & 3.21 & $<0.01$ & $<0.01$ & NS \\
\hline Wort, $200 \mu M$ & $3.43^{\mathrm{c}}$ & $2.06^{\mathrm{x}}$ & $3.21^{\mathrm{y}}$ & 2.79 & 3.32 & $<0.01$ & 0.01 & 0.06 \\
\hline
\end{tabular}

${ }^{\mathrm{a}-\mathrm{c}}$ Means with different superscripts $(\mathrm{a}, \mathrm{b}$, and $\mathrm{c})$ in the UN column were different $(P \leq 0.05)$ using the least-significant difference test.

${ }^{\mathrm{x}, \mathrm{y}}$ Means that are lower $(P \leq 0.05)$ than the control within the Sal column are designated with a superscript x; means that are greater $(P \leq$ 0.05) than the control within the Glc column are designated with a superscript y.

${ }^{1}$ Ruminal fluid in beakers with a control (0.1\% dimethyl sulfoxide, DMSO) or DMSO with insulin, sodium nitroprusside (Snp), or wortmannin (Wort) at the indicated final concentrations and incubated anaerobically at $39^{\circ} \mathrm{C}$ for $3 \mathrm{~h}$ before capillary tubes were inserted into beakers for 20 min. The pooled SEM for beaker treatments (SEM within a row and pooled for all rows) was 0.10.

${ }^{2}$ Unsealed (UN) capillary tubes were used to standardize protozoal counts among beakers. For the UN column, the effect of beaker treatment was $P<0.01$. The pooled SEM for capillary tube treatments (SEM within a column and pooled for all columns) was 0.13.

${ }^{3}$ Sealed capillary tube treatments: saline (Sal, $0.9 \%$ ) or saline containing final concentrations of glucose at $1 \mathrm{M}(\mathrm{Glc})$, soy peptides at $1 \mathrm{~g} / \mathrm{L}$ (Pep), or their combination $(\mathrm{Glc}+\mathrm{Pep})$. When covariate-adjusted to UN, a beaker treatment $\times$ capillary tube treatment interaction $(P<0.01)$ was observed. Using the SAS Slice command (SAS Institute Inc., Cary, NC) within columns, Sal and Glc were $P=0.01$ and other slices were $P>0.10$. ${ }^{4}$ Contrasts among covariate-adjusted means within a row: main effects of Glc (Sal and Pep vs. Glc and Glc + Pep), main effects of Pep (Sal and Glc vs. Pep and Glc + Pep), and the interaction of Glc and Pep (Glc $\times$ Pep) at the probabilities shown. 
Table 2. Covariate-adjusted $\log _{10}$ counts of isotrichids in empty and unsealed (UN) capillary tubes or in capillary tubes containing saline or chemosensing compounds before sealing and placement in beakers containing rumen fluid that was preincubated for $3 \mathrm{~h}$ with sensitizing compounds in experiment 2

\begin{tabular}{lccccc}
\hline & \multicolumn{5}{c}{ Capillary tube treatment $^{2}$} \\
\cline { 2 - 6 } & & \multicolumn{4}{c}{ Covariate-adjusted to UN $^{3}$} \\
\cline { 3 - 6 } $\begin{array}{l}\text { Beaker } \\
\text { treatment }^{1}\end{array}$ & $\mathrm{UN}$ & $\mathrm{Sal}$ & Glc & Pep & Glc + Pep \\
\hline Control & 1.75 & 1.98 & 2.97 & 1.15 & 1.30 \\
Insulin, $2.5 \mu M$ & 1.71 & 1.43 & 2.32 & 0.99 & 1.57 \\
Insulin, $25 \mu M$ & 1.76 & 1.60 & 2.41 & 1.21 & 1.54 \\
Snp, $50 \mu M$ & 1.63 & 1.34 & 2.06 & 1.23 & 1.89 \\
Snp, $500 \mu M$ & 1.68 & 1.13 & 2.36 & 0.98 & 1.76 \\
Wort, $20 \mu M$ & 1.83 & 1.80 & 2.53 & 1.12 & 1.70 \\
Wort, $200 \mu M$ & 1.65 & 1.61 & 1.66 & 1.08 & 1.76 \\
\hline
\end{tabular}

${ }^{1}$ Ruminal fluid in beakers with a control (0.1\% dimethyl sulfoxide, DMSO) or DMSO with insulin, sodium nitroprusside (Snp), or wortmannin (Wort) at the indicated final concentrations and incubated anaerobically at $39^{\circ} \mathrm{C}$ for $3 \mathrm{~h}$ before capillary tubes were inserted into beakers for $20 \mathrm{~min}$. The main effect for beaker treatments was $P=0.10$, and the main effect means (average within a row) were 1.85, 1.58, 1.69, 1.63, 1.56, 1.79, and 1.53 for control; insulin, $2.5 \mu M$; insulin, $25 \mu M$; Snp, $50 \mu M$; Snp, $500 \mu M$; Wort, $20 \mu M$; and Wort, 200 $\mu M$, respectively (pooled SEM was 0.10 ).

${ }^{2}$ Unsealed (UN) capillary tubes were used to standardize protozoal counts among beakers. For the UN column, the effect of beaker treatment was $P>0.10$. The pooled SEM for capillary tube treatments (SEM within a column and pooled for all columns) was 0.38 .

${ }^{3}$ Sealed capillary tube treatments: saline (Sal, $0.9 \%$ ) or saline containing final concentrations of glucose at $1 \mathrm{M}$ (Glc), soy peptides at $1 \mathrm{~g} / \mathrm{L}(\mathrm{Pep})$, or their combination (Glc + Pep). When covariate-adjusted to UN, no beaker treatment $\times$ capillary tube treatment interaction was observed $(P>0.10)$. The main effect means (average within a column) were $1.71,1.56,2.33,1.11$, and 1.65 for UN, Sal, Glc, Pep, and Glc + Pep, respectively. We detected main effects of glucose (Sal and Pep vs. Glc and Glc + Pep; $P<0.01$ ) and peptides (Sal and Glc vs. Pep and Glc + Pep; $P<0.01)$ but no interaction among Glc and Pep $(P>0.10)$.

that wortmannin and Snp both decreased net swimming of entodiniomorphids, and wortmannin interfered with uptake of fluorescent beads, supporting these conclusions.

Because of the interaction between beaker and sealed capillary tube treatments, the sealed capillary tube treatments were compared within row (Table 1). Both glucose and peptides increased chemotaxis for entodiniomorphids, regardless of beaker treatments. Essentially, the capillary tube treatments were additive or else Glc $\times$ Pep interactions would be significant. Only the aforementioned Snp $(P=0.05)$ and wortmannin $(P=0.06)$ treatments had Glc $\times$ Pep interactions because of their lower counts within the Sal column; as explained previously, these results likely were a result of less random swimming into saline for these treatments. Thus, the major explanation for the beaker treatment $\times$ sealed capillary tube treatment interaction $(P<0.01)$ for entodiniomorphids was a result of Snp and wortmannin enhancing chemotaxis toward glucose (discussed previously).

For isotrichids, we detected no effect $(P>0.10)$ of beaker treatment for the UN capillary tubes (Table 2) and no beaker treatment $\times$ sealed capillary tube treatment interaction $(P>0.10)$. We did note tendencies $(P \leq 0.10)$ for decreased chemotaxis for the main effect means of the higher Snp $(500 \mu M)$ and wortmannin
$(200 \mu M)$ treatments compared with the beaker control; however, because the main effect of beaker treatment was $P=0.42$, these results are not statistically supported. We detected a main effect $(P<0.01)$ of glucose in sealed capillary tubes, which was expected based on our previous study (Diaz et al., 2014b). In contrast with that study, but consistent with subsequent results (Diaz et al., 2014a), peptides decreased $(P<0.01)$ isotrichid counts in sealed capillary tubes in the current experiment, suggesting that peptides acted as a chemorepellent. Chemorepellancy to peptides has been observed in Tetrahymena (Kohidai et al., 2003).

While counting, we noted that Snp and wortmannin promoted the formation of large vacuoles: 5.1 and $9.3 \%$ of entodiniomorphids had visible vacuoles for Snp at 50 and $500 \mu M$, and 7.6 and $8.0 \%$ had vacuoles at 20 and $200 \mu M$ wortmannin, respectively $(\mathrm{SE}=2.1 \%$; data not shown). The percentage of isotrichids with vacuoles was $2.6,3.1,1.5$, and $4.5 \%$, respectively (SE $=2.5$; data not shown). These vacuoles were never visualized in any other treatments, even though the DMSO vehicle was at the same concentration in all treatments, including the control. Vacuolization (visualization of fluid-filled membranes) increased with the dose response to wortmannin in Tetrahymena (Nam et al., 2009). Wortmannin's vacuolization responses in Tetrahymena were also associated with hypersecretion 
of lysosomal enzymes and disrupted $\mathrm{Ca}^{2+}$ homeostasis (Leondaritis et al., 2005; Deli et al., 2008). The stimulation of Tetrahymena growth resulting from Snp could be reversed or become antagonistic, depending on Snp concentration, cell density, and other factors (Christensen et al., 1996).

\section{Experiment 3: Preincubation with Genistein with GTP as a Chemorepellant}

In experiment 3 , UN capillary tubes were analyzed to test effects of cell counts during incubation of beaker treatments (Figure 3A). Beaker treatments had no effect on entodiniomorphids or isotrichids. After covariate-adjustment of sealed capillary tube treatments, no interactions $(P>0.10)$ were detected among beaker and sealed capillary tube treatments. Therefore, we assessed main effect means for which there were no differences $(P>0.10)$ in beaker treatments (averaged over capillary tube treatments) for entodiniomorphids or isotrichids (Figure 3B). We did observe differences $(P<0.01)$ among main effect means for sealed capillary tube treatments for both entodiniomorphids and isotrichids (Figure 3C). Glucose alone (no GTP added to the sealed capillary tubes) increased $(P \leq 0.05)$ chemotaxis compared with Sal for both groups; however, unlike entodiniomorphids, which had no response to GTP $(P>0.10)$, the $100 \mu M$ concentration of GTP added to glucose (Glc + GTP treatment) decreased $(P \leq 0.05)$ chemotaxis by isotrichids compared with only glucose (Glc treatment). We chose not to use GTP alone in capillary tubes (without glucose) because we assumed counts would be less than those in saline and therefore difficult to record with satisfactory precision.

In this experiment, neither genistein nor GTP affected chemotaxis toward glucose for entodiniomorphids $(P>0.10)$. This might be due to the lack of GTP receptors on entodiniomorphid cell membranes. Entodiniomorphids have defined patches of cilia near their mouths and use them for movement but also for feeding on particulates (Williams and Coleman, 1992). Results are less clear cut for isotrichids. Chemoattraction to glucose was inhibited by $100 \mu M$ GTP $(P \leq$ $0.05)$, but this effect tended $(P=0.12)$ to be reversed when cells were incubated in the presence of genistein (data not shown). Guanosine triphosphate avoidance was reputed to be blocked by genistein (through an RTK) but also postulated to be blocked by a nitric oxide inhibitor (note that Snp is a nitric oxide activator) and therefore through decreased PKG signaling in Tetrahymena (Bartholomew et al., 2008). Other GTPbinding receptors might open calcium channels, as suggested for Paramecium (Sehring and Plattner, 2004). Thus, other mechanisms might have compensated for
A) Beaker treatments with unsealed capillary tubes

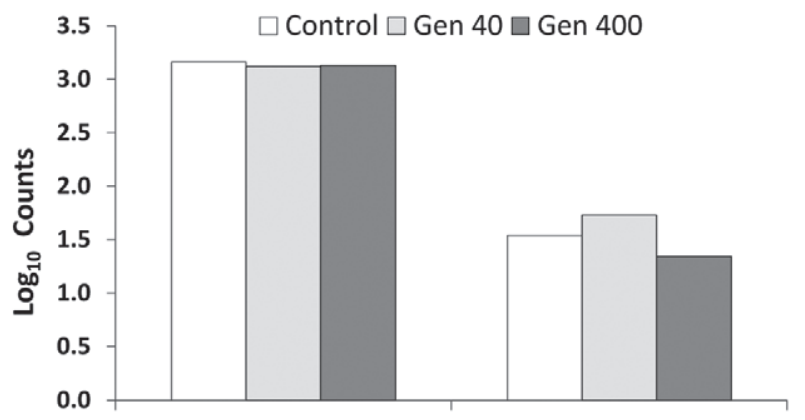

B) Main effects of beaker treatments with sealed capillary tubes

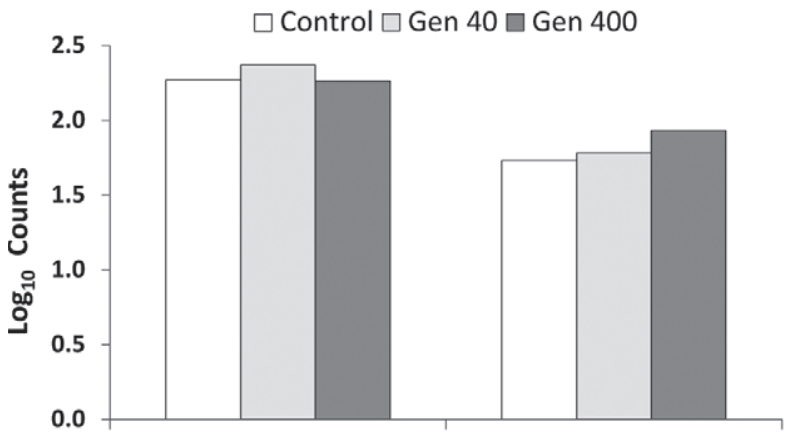

C) Main effects of sealed capillary tube treatments

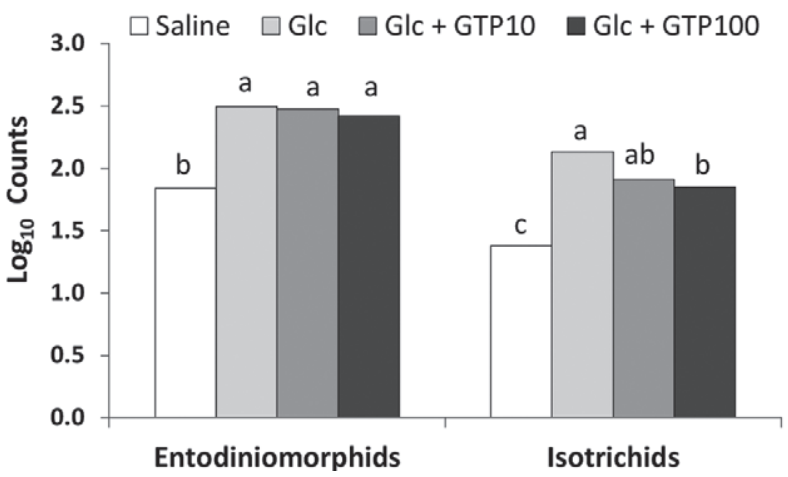

Figure 3. $\log _{10}$ counts of entodiniomorphids or isotrichids in capillary tubes placed in beakers containing rumen fluid that was previously dosed and incubated with solvent (control) or genistein at $40 \mu M$ (Gen 40) or $400 \mu M$ (Gen 400) for 30 min in experiment 3. (A) Empty and unsealed (UN) capillary tubes for which beaker treatment had no effect $(P>0.10)$; pooled $\mathrm{SE}=0.336$ and 0.146 for entodiniomorphids and isotrichids, respectively. For sealed capillary tubes that were covariate-adjusted to the respective UN counts, no beaker $\times$ capillary tube interaction $(P>0.10)$ was observed. Therefore, main effect means for beaker treatment and capillary tube treatments are presented in panels B and C, respectively. (B) No differences were detected among main effect means for beaker treatment $(P>0.10)$; pooled SE were 0.053 and 0.101 for entodiniomorphids and isotrichids, respectively). (C) Sealed capillary tube treatments were saline or saline containing glucose at $1 M(\mathrm{Glc})$, or Glc plus guanosine triphosphate (GTP) at 10 (GTP 10) or 100 (GTP 100) $\mu M$. For entodiniomorphids (pooled SE $=$ 0.069 ) and isotrichids (pooled SE $=0.110$ ), the main effect of capillary tubes treatment was $P<0.01$, so means with different letters (a, b, or c) are different $(P \leq 0.05)$. 
genistein's effect on isotrichids. All isotrichids have cilia over their entire cell, swim in a helical pattern, and exhibit a high degree of migratory behavior to consume or transport sugars rapidly and subsequently swim or sediment back to the ventral rumen (Dehority, 2003). Thus, high concentrations of GTP in experiment 3 or peptides in experiment 2 could signal lytic conditions and stimulate repellence behavior in vivo to avoid the excessive lysis that has been noted in vitro resulting from rapid and potentially excessive synthesis of storage polysaccharide (Hall, 2011).

\section{CONCLUSIONS}

Results support dose-responsive insulin recovery from wortmannin inhibition by En. caudatum and Ep. caudatum cultures, depending on wortmannin concentration. Sodium nitroprusside at $500 \mu M$ and wortmannin at $200 \mu M$ decreased random swimming into the Sal capillary tubes by these 2 entodiniomorphids. However, these inhibitors increased chemotaxis toward glucose in capillary tubes, probably mediated by separate mechanisms: direct activation of PKG to enhance circular swimming (Snp) or indirectly through depleted energy sensitizing chemotaxis (wortmannin). Both glucose and peptides were chemotactic to entodiniomorphids, whereas isotrichids were highly chemoattracted to glucose but chemorepelled by the soy peptides used in this study even when combined with glucose. No consistent effect of preincubation with insulin, Snp, or wortmannin was noted on the chemotactic behavior of isotrichids. For isotrichids, GTP in capillary tubes reversed chemoattraction to glucose, whereas no response was noted for entodiniomorphids. Chemotaxis and repellence appears to be more sensitive in isotrichids, apparently in coordination with their migratory ecology. In contrast, entodiniomorphids are constantly but less acutely chemoattracted to glucose and peptides; the responses to preincubation treatments suggest that chemotaxis is probably integrated with their ecology for more continual feeding and slower hydrolysis of particulate matter and bacteria.

\section{ACKNOWLEDGMENTS}

Research was supported by state and federal funds appropriated to the Ohio Agricultural Research and Development Center, The Ohio State University. Research funds were provided by the USDA National Research Initiative Grant 2008-35206-18847. This paper is manuscript number 21/13AS. We thank our colleagues Timothy Hackmann (University of Florida, Gainesville), Mark Morrison (University of Queensland, Brisbane, Australia), and Zhongtang Yu (The Ohio State
University, Columbus) for valuable discussions during the design and discussion of this research.

\section{REFERENCES}

Abe, M., T. Iriki, N. Tobe, and H. Shibui. 1981. Sequestration of holotrich protozoa in the reticulo-rumen of cattle. Appl. Environ. Microbiol. 41:758-765.

Bartholomew, J., J. Reichart, R. Mundy, J. Rechtenwald, S. Keyser, M. Riddle, and H. Kuruvilla. 2008. GTP avoidance in Tetrahymena thermophila requires tyrosine kinase activity intracellular calcium, NOS, and guanylyl cyclase. Purinergic Signal. 4:171-181.

Berndtson, W. E. 1991. A simple, rapid and reliable method for selecting or assessing the number of replicates for animal experiments. J. Anim. Sci. 69:67-76.

Cho, J. Y., and J. Park. 2008. Contribution of natural inhibitors to the understanding of the PI3K/PDK1/PKB pathway in the insulin-mediated intracellular signaling cascade. Int. J. Mol. Sci. 9:2217-2230.

Christensen, S. T., C. F. Guerra, A. Awan, D. N. Wheatley, and P. Satir. 2003. Insulin receptor-like proteins in Tetrahymena thermophila ciliary membranes. Curr. Biol. 13:R50-R52.

Christensen, S. T., K. Kemp, H. Quie, and L. Rasmussen. 1996. Cell death, survival and proliferation in Tetrahymena thermophila. Effects of insulin, sodium nitroprusside, 8-bromo cyclic GMP, $\mathrm{N}^{\mathrm{G}}$ methyl-L-arginine and methylene blue. Cell Biol. Int. 20:653-666.

Christopher, G. K., and C. A. Sundermann. 1992. Conventional and confocal microscopic studies of insulin receptor induction in Tetrahymena pyriformis. Exp. Cell Res. 201:477-484.

Csaba, G., P. Kovacs, and E. Pallinger. 2008. Comparison of the insulin binding, uptake and endogenous insulin content in longand short-term starvation in Tetrahymena. Cell Biochem. Funct. 26:64-69.

Csaba, G., P. Kovacs, L. Tothfalusi, and E. Pallinger. 2006. Effects of extremely low concentrations of hormones on the insulin binding of Tetrahymena. Cell Biol. Int. 30:957-962.

Dehority, B. A. 1993. Laboratory Manual for Classification and Morphology of Rumen Ciliate Protozoa. CRC Press Inc., Boca Raton, FL.

Dehority, B. A. 1998. Generation times of Epidinium caudatum and Entodinium caudatum, determined in vitro by transferring at various time intervals. J. Anim. Sci. 76:1189-1196.

Dehority, B. A. 2003. Rumen Microbiology. Nottingham University Press, Nottingham, UK.

Dehority, B. A. 2004. In vitro determination of generation times for Entodinium exiguum, Ophryoscolex purkynjei, and Eudiplodinium maggii. J. Eukaryot. Microbiol. 51:333-338.

Dehority, B. A. 2010. Physiological characteristics of several rumen protozoa grown in vitro with observations on within and among species variation. Eur. J. Protistol. 46:271-279.

Deli, D., G. Leondaritis, A. Tiedtke, and D. Galanopoulou. 2008. Deficiency in lysosomal enzyme secretion is associated with upregulation of phosphatidylinositol 4-phosphate in Tetrahymena. J. Eukaryot. Microbiol. 55:343-350.

Diaz, H. L., K. N. Barr, K. R. Godden, J. E. Plank, I. Zapata, A. N. Schappacher, M. P. Wick, and J. L. Firkins. 2014a. Eukaryotic inhibitors or activators elicit responses to chemosensory compounds by ruminal isotrichid and entodiniomorphid protozoa. J. Dairy Sci. 97:2254-2269. 10.3168/jds.2013-7698.

Diaz, H. L., S. K. R. Karnati, M. A. Lyons, B. A. Dehority, and J. L. Firkins. 2014b. Chemotaxis toward carbohydrates and peptides by mixed ruminal protozoa when fed, fasted, or incubated with polyunsaturated fatty acids. J. Dairy Sci. 97:2231-2243. 10.3168/ jds.2013-7428.

Firkins, J. L., A. N. Hristov, M. B. Hall, G. A. Varga, and N. R. StPierre. 2006. Integration of ruminal metabolism in dairy cattle. J. Dairy Sci. 89(E. Suppl.):E31-E51.

Firkins, J. L., and Z. Yu. 2006. Characterisation and quantification of the microbial populations in the rumen. Pages 19-54 in Ruminant Physiology, Digestion, Metabolism and Impact of Nutrition 
on Gene Expression, Immunology and Stress. K. Sejrsen, T. Hvelplund, and M. O. Nielsen, ed. Wageningen Academic Publishers, Wageningen, the Netherlands.

Firkins, J. L., Z. Yu, and M. Morrison. 2007. Ruminal nitrogen metabolism: Perspectives for integration of microbiology and nutrition for dairy. J. Dairy Sci. 90(E. Suppl.):E1-E16.

Gonda, K., K. Oami, and M. Takahashi. 2007. Centrin controls the activity of the ciliary reversal-coupled voltage-gated $\mathrm{Ca}^{2+}$ channels $\mathrm{Ca}^{2+}$-dependently. Biochem. Biophys. Res. Commun. 362:170176 .

Hall, M. B. 2011. Isotrichid protozoa influence conversion of glucose to glycogen and other microbial products. J. Dairy Sci. 94:4589 4602.

Hernandez, Y., G. Zamora, S. Ray, J. Chapoy, E. Chavez, R. Valvarde, E. Williams, S. B. Aley, and S. Das. 2007. Transcriptional analysis of three major putative phosphatidylinositol kinase genes in a parasitic protozoan, Giardia lamblia. J. Eukaryot. Microbiol. 54:29-32.

Hook, S. E., J. Dijkstra, A.-D. G. Wright, B. W. McBride, and J. France. 2012. Modeling the distribution of ciliate protozoa in the reticulo-rumen using linear programming. J. Dairy Sci. 95:255265.

Hristov, A. N., and J.-P. Jouany. 2005. Factors affecting the efficiency of nitrogen utilization in the rumen. Pages 117-166 in Nitrogen and Phosphorus Nutrition of Cattle and Environment. A. N. Hristov and E. Pfeffer, ed. CAB International, Wallingford, UK.

Kaczanowska, J., S. Kaczanowski, M. Kiersnowska, H. Fabczak, K. Tulodziecka, and A. Kaczanowski. 2008. Acquisition of cell polarity during cell cycle and oral replacement in Tetrahymena. Int. J. Dev. Biol. 52:249-258.

Kisidayová, S., and Z. Varadyova. 2005. Effect of insulin on in vitro fermentation activity of microorganism community of rumen ciliate Entodinium caudatum culture. Cell Biol. Int. 29:147-152.

Kohidai, L., K. Török, E. Illyés, J. Tamási, F. Sebestyén, O. Láng, G. Csaba, and F. Hudecz. 2003. Characterization of chemotactic ability of peptides containing $\mathrm{N}$-formyl-methionyl residues in Tetrahymena fMLP as a targeting ligand. Cell Biol. Int. 27:695-700.

Kovacs, P., and E. Pallinger. 2003. Phosphatidylinositol 3-kinase-like activity in Tetrahymena. Effects of wortmannin and LY 294002. Acta Protozool. 42:277-285.

Leick, V., T. C. Bøg-Hansen, and H. A. Juhl. 2001. Insulin/FGF-binding cilliary membrane glycoprotein from Tetrahymena. J. Membr. Biol. 181:47-53.

Leick, V., and F. Chen. 2004. Chemosensory behaviour and ciliary cyclic GMP-dependent protein kinase in Tetrahymena thermophila. Eur. J. Protistol. 40:303-312.

Leick, V., C. Iversen, K. Kemp, and S. T. Christensen. 1997. Protein kinase inhibitors abolish adaptive cell behavior in Tetrahymena. Acta Protozool. 36:249-260.

Lenard, J. 1992. Mammalian hormones in microbial cells. Trends Biochem. Sci. 17:147-150.

Leondaritis, G., T. Sarri, I. Dafnis, A. Efstathiou, and D. Galanopoulou. 2011. Biochemical and genetic evidence for the pres- ence of multiple phosphatidylinositol- and phosphatidylinositol 4,5-bisphosphate-specific phospholipases $\mathrm{C}$ in Tetrahymena. Eukaryot. Cell 10:412-422.

Leondaritis, G., A. Tiedtke, and D. Galanopoulou. 2005. D-3 phosphoinositides of the ciliate Tetrahymena: Characterization and study of their regulatory role in lysosomal enzyme secretion. Biochim. Biophys. Acta 1745:330-341.

Morrison, H. G., G. Zamora, R. K. Campbell, and M. L. Sogin. 2002. Inferring protein function from genomic sequence: Giardia lamblia expresses a phosphatidylinositol kinase-related kinase similar to yeast and mammalian TOR. Comp. Biochem. Physiol. B Biochem. Mol. Biol. 133:477-491.

Nam, S.-W., S.-T. Kim, K.-M. Lee, S. H. Kim, S. Kou, J. Lim, H Hwang, M. K. Joo, B. Jeong, S. H. Yoo, and S. Park. 2009. NMethyl-D-aspartate receptor-mediated chemotaxis and $\mathrm{Ca}^{2+}$ signaling in Tetrahymena pyriformis. Protist 160:331-342.

Pagliassotti, M. J., Y. Wei, and D. Wang. 2007. Insulin protects liver cells from saturated fatty acid-induced apoptosis via inhibition of c-Jun NH2 terminal kinase activity. Endocrinology 148:3338 3345 .

Paul, R. G., R. D. Butler, and A. G. Williams. 1989. Ultrastructure of the rumen ciliate Dasytricha ruminantium. Eur. J. Protistol. $24: 205-215$

Renouf, M., and S. Hendrich. 2011. Bacteroides uniformis is a putative bacterial species associated with the degradation of the isoflavone genistein in human feces. J. Nutr. 141:1120-1126.

Russell, J. B., and J. L. Rychlik. 2001. Factors that alter rumen microbial ecology. Science 292:1119-1122.

Sehring, I. M., and H. Plattner. 2004. $\mathrm{Ca}^{2+}$ oscillations mediated by exogenous GTP in Paramecium cells: Assessment of possible $\mathrm{Ca}^{2+}$ sources. Cell Calcium 36:409-420.

Smith, J. J., J. S. Yakisich, G. M. Kapler, E. S. Cole, and D. P. Romero. 2004. A $\beta$-tubulin mutation selectively uncouples nuclear division and cytokinesis in Tetrahymena thermophila. Eukaryot. Cell 3:1217-1226.

Sylvester, J. T., S. K. R. Karnati, B. A. Dehority, M. Morrison, G. L. Smith, N. R. St-Pierre, and J. L. Firkins. 2009. Rumen protozoa decrease generation time and adjust $18 \mathrm{~S}$ ribosomal DNA copies to adapt to decreased transfer interval, starvation, and monensin. J. Dairy Sci. 92:256-269.

Williams, A. G. 1979. The selectivity of carbohydrate assimilation by the anaerobic rumen ciliate Dasytricha ruminantium. J. Appl. Bacteriol. 47:511-520.

Williams, A. G., and G. S. Coleman. 1992. The Rumen Protozoa. Springer-Verlag, New York, NY.

Williams, Y. J., S. M. Rea, S. Popovski, C. Pimm, A. J. Williams, A. F. Toovey, L. C. Skillman, and A.-D. G. Wright. 2008. Responses of sheep to a vaccination of entodinial or mixed rumen protozoal antigens to reduce rumen protozoal numbers. Br. J. Nutr. 99:100-109. 